\title{
A catchment-scale irrigation systems model for sugarcane Part 1: Model development
}

\author{
NG Moult ${ }^{1}$, NL Lecler ${ }^{1,2 *}$, JC Smithers ${ }^{1}$ and DJ Clark ${ }^{1}$ \\ ${ }^{1}$ School of Bioresources Engineering and Environmental Hydrology, University of KwaZulu-Natal, Private Bag X01, \\ Scottsville, 3209, South Africa \\ ${ }^{2}$ South African Sugarcane Research Institute, Private Bag X02, Mount Edgecombe, 4300, South Africa
}

\begin{abstract}
In South Africa, the demand for water exceeds available supplies in many catchments. In order to justify existing water requirements and to budget and plan in the context of growing uncertainty regarding water availability, a model to assist in the assessment and management of catchment water supply and demand interactions, and the associated impacts on the profitability of irrigated sugarcane, has been developed. The model, ACRUCane, operates as a submodel within the $A C R U$ agrohydrological model and simulates the water budget of a field of irrigated sugarcane. The water budget is based on the integration of several widely accepted algorithms and concepts, accounts for different irrigation system types performing at different levels of uniformity and different water management strategies. Furthermore, it can simulate a wide variety of water availability scenarios and constraints through its link with $A C R U$ simulated hydrology. The crop yield algorithms used in the model were verified using data from three different irrigation trials with widely varying irrigation treatments, where the model was shown to adequately distinguish the impacts of different watering strategies on crop yields. A description of the model algorithms and results from verification studies are presented in this paper. Application of the model is presented in a companion paper.
\end{abstract}

Keywords: ACRUCane, irrigation systems, water management, crop modelling, hydrology, water resources, sugarcane

\section{Introduction}

The demand for water exceeds available supplies in many catchments in South Africa (NWRS, 2004). Since a substantial amount of water is assigned to irrigated agriculture (Ascough and Kiker, 2002), farmers are facing increasing pressure to use water more effectively and to justify existing water use. In order to justify existing water requirements and to budget and plan in the context of growing uncertainty regarding water availability, a tool to assist in the assessment and management of catchment water supply and demand interactions, and the associated impacts on the profitability of irrigated sugarcane, is needed.

While there have been many useful model developments for sugarcane and water resources management, none of these provide all the necessary decision support information in an integrated fashion. Therefore, the development of a catchment-scale irrigation systems model was initiated. The model capabilities required to provide adequate decision support information were identified by Moult (2005) as being the following:

- Modelling the soil water balance at a field scale for irrigated areas and at a catchment scale for non-irrigated areas,

- Linking an accurate estimation of crop water requirement for an irrigated area with the availability of water at a catchment scale,

- Explicitly accounting for the impact of the performance of different irrigation systems, including non-uniform water applications, on the hydrology and, ultimately, on the

* To whom all correspondence should be addressed.

용 +2731 508 7431; fax: +2731 508 7597;

e-mail: Neil.Lecler@sugar.org.za

Received 28 March 2008; accepted in revised form 28 November 2008 sugarcane yield of an irrigated area, and

- Assessing the impact of different supply constraints on sugarcane yield, and estimating both sugarcane and sucrose yield.

The objective of this paper is to describe the concepts and development of a model to meet the above requirements and to report on verification of sugarcane and sucrose yields simulated by the model.

\section{Methodology}

The development of the conceptual model involved a review of the available models with respect to their potential to meet the objectives of the project. During the reviewing process concepts and algorithms pertinent to the development of the model were selected such that, when integrated, they would meet the stated model requirements. The models reviewed included: SWB (Campbell and Diaz, 1988). CANEGRO (Inman-Bamber, 1991), ACRU (Schulze, 1995), APSIM (McCown et al., 1996), CANESIM (Singels et al., 1998) and ZIMsched 2.0 (Lecler, 2003). The FAO Irrigation and Drainage Paper No. 56 (FAO 56, Allen et al., 1998) was also reviewed as it is fundamental to the water budget used in ZIMsched 2.0 and SWB. Full reviews of these models are provided by Moult (2005). A conclusion of the review process was that despite their respective strengths, none of these models and associated algorithms incorporated all the desired system processes in an integrated fashion. In particular none were able to represent the link between catchment hydrology, water availability, irrigation demand, non-uniform irrigation water applications and associated crop yields The development of the ACRUCane model is described in the following section. 


\section{Model description}

The water budget in ACRUCane is based primarily on a unique integration and refinement of robust algorithms from FAO 56 (Allen et al., 1998) and the $A C R U$ model (Schulze, 1995) and is very similar to the water budget used in ZIMsched 2.0 (Lecler, 2003)

The $A C R U$ model is a catchment-scale agrohydrological model capable of simulating catchment hydrology and many different water supply scenarios (Lecler et al., 1995). Consequently, the $A C R U$ model was used to simulate runoff from the catchment and water storage which was linked to a smaller submodel, developed to simulate the water budget of an irrigated field of sugarcane and the associated yields when irrigated with different types of irrigation systems. This model is referred to as ACRUCane. A description of the fundamental aspects of the water budget for ACRUCane follows.

\section{Runoff}

Wetting events occur as a result of either rainfall or irrigation, both of which can potentially generate runoff. Runoff from the irrigated area is simulated using an equation developed by the Soil Conservation Service (USDA, 1985) and adapted for use in South Africa by Schmidt and Schulze (1987) and Schulze et al. (1995)

$$
Q=(P I-c S)^{2} /(P I+S(1-c))
$$

where:

$Q=$ surface runoff depth $(\mathrm{mm})$

$P I=$ daily wetting amount $(\mathrm{mm})$, i.e. rainfall and/or irrigation

$c=$ coefficient of initial abstraction

$S=$ potential maximum water retention of the soil, taken as the soil water deficit below porosity, prior to a wetting event $(\mathrm{mm})$

Rainfall and/or irrigation that do not generate runoff are assumed to infiltrate into the soil immediately after the wetting event has occurred. Rates of infiltration are not simulated in ACRUCane Once in the soil profile, water leaves the soil through either evapotranspiration or deep percolation.

\section{Evapotranspiration}

Evapotranspiration from the cropped surface is determined using the dual crop coefficient methodology described by Allen et al. (1998).

$$
E T_{c}=\left(K_{c b}+K_{e}\right) \cdot E T_{0}
$$

where:

$$
\begin{aligned}
E T_{c}= & \text { evaporation from a cropped surface }(\mathrm{mm}) \\
K_{c b}= & \text { basal crop coefficient } \\
K_{e}= & \text { coefficient controlling evaporation from the soil } \\
E T_{0}= & \text { reference evaporation from a hypothetical short- } \\
& \text { grass surface }(\mathrm{mm})
\end{aligned}
$$

Using dual crop coefficients allows the separation of evaporation from a cropped surface into two processes, namely, transpiration $\left(E_{t}\right.$ in $\left.\mathrm{mm}\right)$ and evaporation from the soil $\left(E_{s}\right.$ in $\left.\mathrm{mm}\right)$. Treating these two processes separately is important because prior to the development of significant canopy cover, water losses are dominated by evaporation from the soil surface. Accurate estimation of $E_{s}$ is important as it can be highly variable and is dependent on the wetting fraction and wetting frequency of the soil (Lecler, 2003).

\section{Drainage}

If, at the end of the day, the soil moisture content of the root zone (the portion of soil occupied by the roots) is above the field capacity (FC) of the soil, then drainage of the profile is initiated. The fraction of moisture above the FC that drains from the soil profile is dependent on the soil textural class and the amount of excess water. Default values for the drainage rate are related to the soil texture, but can be overridden by a user-specified value.

\section{Crop processes}

To aid in simulating the water budget, phenological processes such as root growth and canopy development are modelled. Root growth is simulated using a methodology described by Lecler (2003) and accounts for the crop's increasing access to soil moisture during the course of the growing season. Canopy development is simulated using a model described by Singels and Donaldson (2000) and is used to account for the effects of light interception and soil shading on evaporation of water from the soil and increased crop water usage as the crop grows.

\section{Irrigation systems}

Different types of irrigation system hardware are accounted for in several ways in ACRUCane. The irrigation system type, e.g. 'drip' irrigation, is associated with system specific attributes such as the fraction of soil wetted by irrigation, and whether or not interception of irrigation water applications is simulated. Included in the required input parameter set is an irrigation uniformity index such as the Distribution Uniformity $(D U)$ to enable the simulation of non-uniform irrigation water applications which occur in practice. This is achieved using multiple water budgets and assuming a normal distribution of irrigation depths as described by Lecler (2003) and Ascough and Lecler (2004). The impacts associated with water management are represented through the simulation of a wide range of irrigation scheduling options.

\section{Irrigation scheduling options}

Different irrigation practices impact significantly on the hydrology of the area being irrigated. ACRUCane allows the user a choice of six different modes of irrigation scheduling, which include the four options available in the $A C R U$ model (Schulze, 1995) as well as two additional options. In ACRUCane the irrigation requirement is determined for the scheduling option selected by the user and is then applied at the beginning of each day. Note that in all scheduling options described below, an irrigation requirement is determined. The amount that is actually applied to the crop is limited by water availability from the supply source, and in some cases, the capacity of the irrigation system, i.e. the minimum cycle time.

\section{Option 1 - Refill the soil profile at a specified fraction} of total available water (TAW)

In this mode of scheduling, a user input fraction of TAW is used to determine the maximum allowable depletion of water in the soil profile. Once this level has been reached, an irrigation 
requirement is generated to refill the soil profile to the $\mathrm{FC}$, or to a water level below the FC, thus leaving a portion of the soil water store to be filled by precipitation which may occur. It is an efficient form of irrigation as irrigation is only initiated when it is necessary to prevent crop water stress.

\section{Option 2 - Apply a fixed amount of water in a fixed cycle}

For practical purposes, farmers often irrigate using a fixed cycle and fixed application amount for different times of the year. In ACRUCane, the user selects both the application depth and the interval between applications. The cycle length is assumed to continue throughout the growing season, unless a threshold amount of rainfall occurs which interrupts and causes the irrigation cycle to restart.

\section{Option 3 - Apply a variable amount of water in a fixed cycle}

This mode of irrigation scheduling results in irrigation applied using a fixed cycle length but with varying amounts or irrigation water applied. The user specifies the cycle length and the system capacity. At the beginning of each cycle the depth of water required to fill the soil profile up to the $\mathrm{FC}$ is determined. If the required amount is less than the system capacity then the irrigation requirement is met, otherwise the applied depth is limited by the system capacity. As with Option 1, a certain portion of the soil water store can be left unfilled for potential rainfall events that may supplement irrigation.

\section{Option 4-Duplicate a known irrigation regime}

Using this option the user can simulate a known watering regime, which is read into the model from a user prepared hydrometeorological data file.

\section{Option 5 - Apply irrigation water using a fixed summer and winter cycle}

A fifth scheduling option was created for ACRUCane to enable the model to represent a common irrigation practice of having separate irrigation cycles for the summer and winter seasons. In this option, the user specifies the cycle length, application amount and the starting dates of the summer and winter cycles.

\section{Option 6-Refill the soil profile at specified moisture depletion level}

The sixth option added to ACRUCane is similar to Option 1. However, instead of specifying the fraction of TAM at which irrigation is to take place, the user specifies a fixed depletion level in $\mathrm{mm}$ below $\mathrm{FC}$ at which irrigation is to be triggered. In this way it is possible for the user to apply, say, $25 \mathrm{~mm}$ once the soil water has depleted $30 \mathrm{~mm}$ below FC, leaving $5 \mathrm{~mm}$ to be filled by precipitation.

\section{Water Supply}

A variety of water supply options can be simulated by $A C R U$ Cane through the $A C R U$ model. These options are illustrated in Fig. 1. The user can thus quantify the impact of different water supply options and constraints on the water budget and ultimately the yield of an irrigated sugarcane crop.

\section{Yield}

To be able to simulate the impact of different management practices effectively, types of irrigation systems, water supply limitations and environmental conditions on sugarcane yield, it is necessary to estimate both the cane yield and quality of cane. In ACRUCane, several algorithms to simulate sugarcane yield and quality are used to provide a range of comparable outputs.

\section{Sucrose}

A conceptually sound radiation-based sucrose yield and biomass accumulation yield algorithm developed for CANEGRO has been included in ACRUCane. This model estimates, inter alia, the sucrose and fibre content of the stalk. The complexities of this model are beyond the scope of this paper and a comprehensive description of this yield model is provided by Singels and Bezuidenhout (2002). Although conceptually superior, this model requires detailed inputs such as daily radiation which may not always be available. For this reason, a conceptually simpler transpiration-based estimated recoverable crystal (ERC) model developed for ZIMsched 2.0 is also included, as it provides a reliable surrogate for sucrose yield.

\section{Estimated recoverable crystal (ERC)}

To estimate $E R C$, an algorithm developed by Doorenbos and Kassam (1979) and modified by De Jager (1994) and Lecler (2003) is used in ACRUCane.

$$
\mathrm{Y}_{\mathrm{a}} / \mathrm{Y}_{\mathrm{p}}=\Sigma\left(1-\mathrm{K}_{\mathrm{yi}}\left(1-\mathrm{T} / \mathrm{T}_{\mathrm{m}}\right)\right)
$$

where:

$Y_{a}=$ actual yield of ERC $\left(\mathrm{t} \cdot \mathrm{ha}^{-1}\right)$

$Y_{p}^{a}=$ potential yield of ERC $\left(\mathrm{t} \cdot \mathrm{ha}^{-1}\right)$

$K_{y i}^{p}=$ yield response factor for the $\mathrm{i}^{\text {th }}$ growth period

$T=$ simulated actual transpiration $(\mathrm{mm})$

$T_{m}=$ simulated maximum transpiration, i.e. with no soil water stress $(\mathrm{mm})$
Figure 1

Schematic Diagram of supply options available in ACRU (Schulze, 1995)

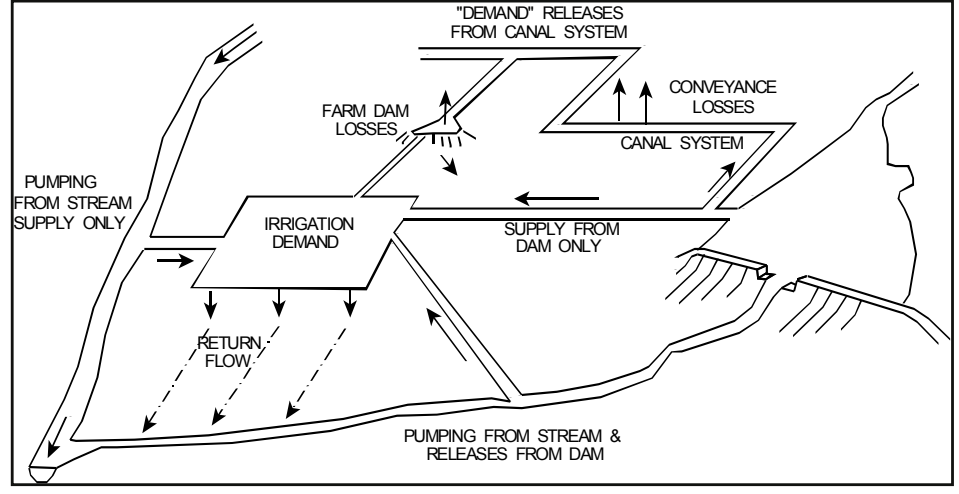


Thus with an estimate of the potential yield of ERC or sucrose $\left(Y_{p}\right)$ it is possible to determine the actual yield $\left(Y_{q}\right)$ by accounting for the impacts of water stress using the ratio of actual to potential transpiration at different times in the growth cycle. The potential sucrose yield is obtained using a modified version of the relationship derived by Thompson (1976), as described by Lecler (2003).

\section{Sugarcane yield}

In addition to the $E R C$ yield estimation, two empirical transpiration-based algorithms are included to estimate tons of sugarcane produced per hectare. The first is the Thompson equation (Thompson, 1976):

$$
Y_{T}=9.53(\Sigma E T) / 100-2.36
$$

where:

$$
\begin{aligned}
& Y_{T}=\text { tons of cane per hectare }\left(\mathrm{t} \cdot \mathrm{ha}^{-1}\right) \\
& \Sigma E T=\text { accumulated actual evapotranspiration }(\mathrm{mm})
\end{aligned}
$$

The second is an equation used in the CANESIM model, developed by fitting a second order polynomial to stalk matter and cumulative transpiration simulated by the CANEGRO model for several widely varying climates (Singels et al., 1999):

$$
Y_{c}=-4 \times 10^{-5}(\Sigma T)^{2}+0.188 \Sigma T-30.737
$$

where:

$$
\begin{aligned}
& Y=\text { tons of cane per hectare }\left(\mathrm{t} \cdot \mathrm{ha}^{-1}\right) \\
& \Sigma T=\text { accumulated actual transpiration }(\mathrm{mm})
\end{aligned}
$$

It must be noted that using transpiration, as opposed to evapotranspiration, is a more desirable option to use as a driver of yield. When using evapotranspiration, evaporation from the soil is inherently included and significant variation, dependent of the wetting fraction and frequency of the irrigation system, can occur prior to extensive canopy development An irrigation system that wets the entire soil surface at a high frequency, such as a centre pivot, would result in high initial evaporation from the soil and thus high evapotranspiration values and simulated yield. However, water loss via soil water evaporation is not used beneficially by the plants and yields simulated under these circumstances can be artificially high.

\section{Verification}

Verification of the yield estimation algorithms in ACRUCane was conducted using irrigation trial data from both La Mercy in KwaZulu-Natal and the Lowveld of Zimbabwe. In this paper a summarised version of the results is presented. For all trials the actual irrigation regime used for the different treatments was replicated in the model. No measure of irrigation uniformity was reported in the trial records, thus for the verification studies, any non-uniformity in irrigation water applications was not represented. A comprehensive description of the trials and presentation of results can be found in Moult (2005).

\section{La Mercy Trial}

The La Mercy trial was initiated by the South African Sugarcane Research Institute. Five different treatments were applied to trial plots, ranging from full irrigation (Treatment 1) to rainfed conditions (Treatment 5), over a 4-year period that included

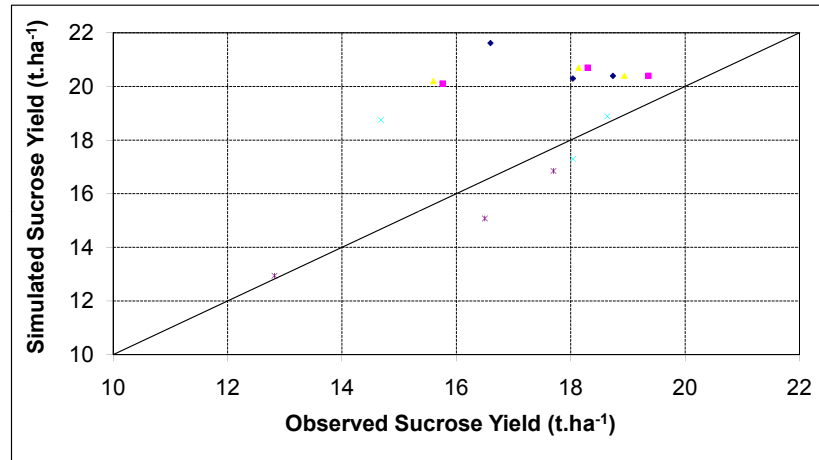

- Treatment 1 - Treatment $2 \quad$ Treatment $3 \times$ Treatment $4 \times$ Treatment 5

Figure 2

Observed and simulated sucrose yields obtained using the ACRUCane model based on Singels and Bezuidenhout (2002) and La Mercy irrigation trial data

one plant crop and three ratoons (a ratoon crop is the new cane which grows from the stubble left behind). Estimates of sugarcane, and sucrose yield were simulated and compared against observed values of sugarcane and sucrose yields for the ratoon crops as the model algorithms were designed to represent ratoon rather than plant crops.

\section{Sucrose yield}

Sucrose yields using the model based on Singels and Bezuidenhout (2002) were estimated to an acceptable degree of accuracy. A scatter plot of simulated and observed sucrose yields and a ' $1: 1$ ' line are shown in Fig. 2.

It is evident from Fig. 2 that the ACRUCane model simulated the drier treatments, such as Treatment 4 and 5, better than the wetter treatments where the sucrose yield was generally overestimated. Statistical results are shown in Table 1.

As evident from Table 1 , the simulated mean $\left(\mathrm{S}_{\text {mean }}\right)$ obtained was marginally higher than the observed mean $\left(\mathrm{O}_{\text {mean }}\right)$. A RMSE of $2.6 \mathrm{t} \cdot \mathrm{ha}^{-1}$ was obtained which is the same as the value obtained by Singels and Bezuidenhout (2002) and indicates that, on average, the simulated yield was within $15 \%$ of the observed yield. The index of agreement (d), as defined by Wilmott (1981), yielded value of 0.65 which, although not close to a perfect agreement of 1 , still indicates a fair model performance.

\begin{tabular}{|c|c|c|c|}
\hline \multicolumn{4}{|c|}{ TABLE 1 } \\
Statistical analysis of simulated vs. \\
observed sucrose yields using the \\
ACRUCane model on La Mercy trial data \\
\hline $\begin{array}{c}\mathbf{O}_{\text {mean }} \\
\left(\mathbf{t} \cdot \mathrm{ha}^{-1}\right)\end{array}$ & $\begin{array}{c}\mathbf{S}_{\text {mean }} \\
\left(\mathbf{t} \cdot \mathrm{ha}^{-1}\right)\end{array}$ & $\begin{array}{c}\text { RMSE } \\
\left(\mathbf{t} \cdot \mathbf{h a}^{-1}\right)\end{array}$ & $\mathbf{d}$ \\
\hline 17.2 & 18.9 & 2.6 & 0.65 \\
\hline
\end{tabular}

\section{Cane yield}

Although two equations were used in ACRUCane to estimate cane yield, only the results using the Thompson equation are shown in this paper. A scatter plot of simulated and observed cane yields and a '1:1' line are shown in Fig. 3.

It is evident from Fig. 3 that yields were underestimated by the ACRUCane. There appears to be no clear trends between wetter or drier treatments although higher yields were underestimated more than lower yields. Statistical results are shown in Table 2. 


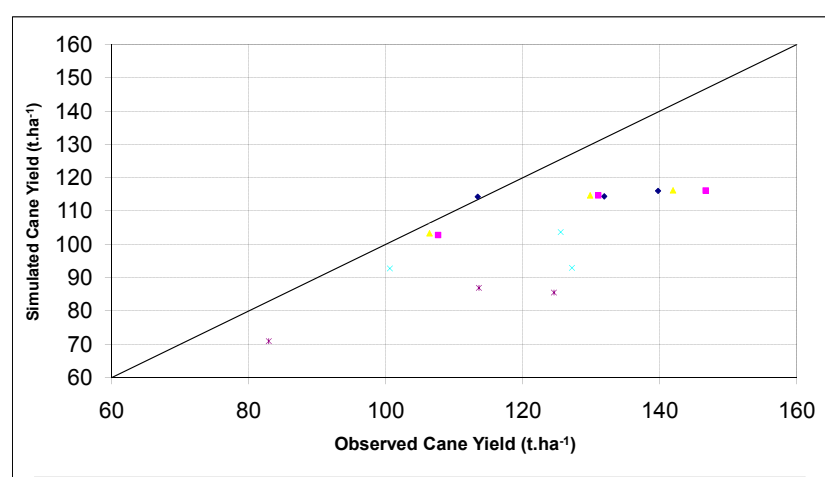

- Treatment $1 \quad$ - Treatment $2 \quad$ Treatment $3 \times$ Treatment $4 \times$ Treatment 5

Figure 3

Observed and simulated sugarcane yields obtained the ACRUCane model on La Mercy irrigation trial data

\begin{tabular}{|c|c|c|c|}
\hline \multicolumn{4}{|c|}{ TABLE 2} \\
Statistical analysis of simulated versus \\
observed sugarcane yield using ACRU- \\
Cane on La Mercy trial data \\
\hline $\begin{array}{c}\mathbf{O}_{\text {mean }} \\
\left(\mathbf{t} \cdot \text { ha }^{-1}\right)\end{array}$ & $\begin{array}{c}\mathbf{S}_{\text {mean }} \\
\left(\mathbf{t} \cdot \mathrm{ha}^{-1}\right)\end{array}$ & $\begin{array}{c}\mathrm{RMSE} \\
\left(\mathbf{t} \cdot \mathrm{ha}^{-1}\right)\end{array}$ & $\mathbf{d}$ \\
\hline 121.5 & 103.0 & 21.7 & 0.659 \\
\hline
\end{tabular}

The models underestimation is confirmed by the $\mathrm{O}_{\text {mean }}$ being considerably higher than $\mathrm{S}_{\text {mean }}$. The RMSE of $21.7 \mathrm{t} \cdot \mathrm{ha}^{-1}$ obtained indicates that, on average, yield was simulated to within $17.9 \%$ of the observed value. An index of agreement of 0.659 indicates a fair agreement between simulated and observed values.

\section{Zimbabwe - Trial 4200/1}

The first set of trial data from Zimbabwe used for verification came from an irrigation trial initiated at the Zimbabwean Sugar Association Experiment Station (ZSAES), which is located near Chiredzi in Zimbabwe. The trial plots were planted to sugarcane in 1966 and the experiments were terminated in 1972. Six different irrigation treatments were used where $50 \mathrm{~mm}$ of irrigation water was applied, each treatment using a different pan factor to estimate the evapotranspiration and hence to schedule the irrigation. A pan factor is defined as the ratio of irrigation applied to accumulated pan evaporation since the previous irrigation application. Applications ranged from full irrigation (Treatment $1-$ pan factor $=1.0$ ) to very dry treatments (Treatment $6-$ pan factor $=0.38$ ). The trial plots had never been planted to sugarcane or any other form of commercial agriculture prior to the experiment. As a result, observed yields were exceptionally high. The mean observed yield of ERC was $16.4 \mathrm{t} \cdot \mathrm{ha}^{-1}$ compared to the mean simulated yield of $13.8 \mathrm{t} \cdot \mathrm{ha}^{-1}$. Since ACRUCane does not account for soil quality, simulated yields tended to be lower than those observed were. Thus relative yields were compared, i.e. yields expressed as a fraction of the maximum value.

\section{ERC yield}

A scatter plot of the results of ERC simulations is shown in Fig. 4. Generally the results in Figure 4 indicate a good correlation between the standardised simulated and observed values. It is evident from Fig. 4 that ERC is slightly underestimated at higher relative yields (wetter treatments) and overestimated for lower relative yields (drier treatments). An explanation for the

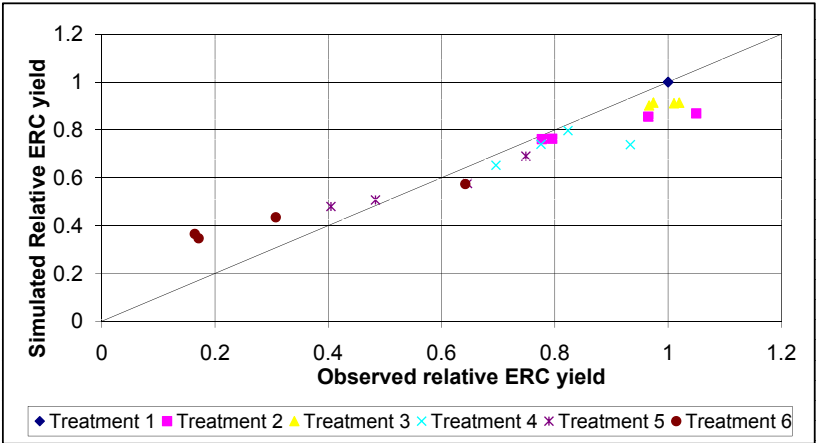

Figure 4

Observed versus simulated relative ERC yields for Trial 4200/1 at ZSAES using the ERC model based on Lecler (2003)

overestimation of lower relative yields is the fact that the canopy model, which is used to 'drive' transpiration, does not account for soil water stress. Since canopy development in ACRUCane depends primarily on temperature, each treatment would have the same simulated canopy and thus the same potential for transpiration. Thus, even very dry treatments would, when simulated, transpire after a wetting event at the same rate as wetter treatments. In practice, crops subjected to severe water stress would have stunted canopies and, even after a wetting event, would not transpire at the same rate as a crop that had been well irrigated. In addition to this, Doorenbos and Kassam (1979) noted that the relationship they derived was not valid for conditions where soil water stress was such that crop water use was reduced to less than half of the potential rate. Statistical results are shown in Table 3.

\begin{tabular}{|c|c|c|c|}
\hline \multicolumn{4}{|c|}{$\begin{array}{c}\text { TABLE } 3 \\
\text { Statistical analysis of standardised } \\
\text { simulated and observed relative ERC } \\
\text { yield for Trial } 4200 / 1 \text { at ZSAES }\end{array}$} \\
\hline $\begin{array}{c}O_{\text {mean }} \\
\left(t \cdot \text { ha }^{-1}\right)\end{array}$ & $\begin{array}{c}S_{\text {mean }} \\
\left(t \cdot \text { ha }^{-1}\right)\end{array}$ & $\begin{array}{l}\text { RMSE } \\
\left(\mathrm{t} \cdot \mathrm{ha}^{-1}\right)\end{array}$ & $d$ \\
\hline 0.765 & 0.741 & 0.097 & 0.96 \\
\hline
\end{tabular}

The standardised $\mathrm{S}_{\text {mean }}$ and $\mathrm{O}_{\text {mean }}$ are very similar in value, and $\mathrm{d}$ is very close to a value of 1.0 , indicating a high level of agreement between simulated and observed values. The RMSE of 0.097 obtained means that, on average, relative yield was estimated within $12 \%$ of the observed relative yield, which is comparable to the value of $6 \%$ obtained by Lecler (2003).

\section{Sugarcane yield}

In the case of cane yield, actual yields were simulated reasonably well for this trial and relative yields were not used to examine results. As shown in Fig. 5 high yields, typically resulting from wetter irrigation treatments, were simulated well by the model. As with ERC yield, lower yields from drier treatments were consistently overestimated by the model. This can be attributed to the fact that the simulated canopy does not account for soil water stress and hence overestimates transpiration for wetter treatments, as explained in the ERC yield analysis. Importantly, the very dry treatments (Treatment 5 and 6) are not irrigation regimes that would be used in practice unless the irrigator was forced to under-irrigate as a result of severe water shortages. Treatments 5 and 6 are the only treatments where the simulated values always exceed the observed values. The summarised results of simulated cane yield are listed in Table 4. 


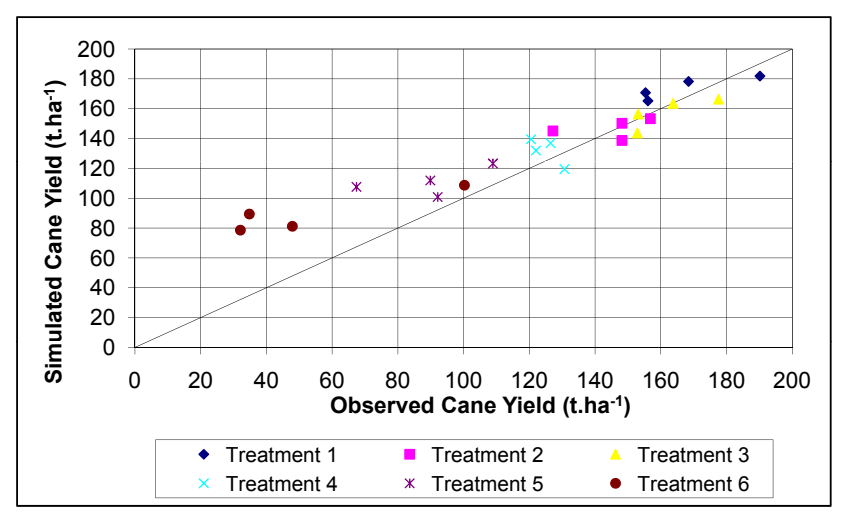

Figure 5

Observed vs. simulated sugarcane yields from trial 4200/1 at ZSAES

\begin{tabular}{|c|c|c|c|}
\hline \multicolumn{4}{|c|}{ TABLE 4 } \\
\multicolumn{3}{|c|}{$\begin{array}{c}\text { Statistical analysis of simulated vs. } \\
\text { observed sugarcane yield from trial } \\
\text { 4200/1 at ZSAES }\end{array}$} \\
\hline $\begin{array}{c}\mathbf{O}_{\text {mean }} \\
\left(\mathbf{t} \cdot \text { ha }^{-1}\right)\end{array}$ & $\begin{array}{c}\mathbf{S}_{\text {mean }} \\
\left(\mathbf{t} \cdot \mathbf{h a}^{-1}\right)\end{array}$ & $\begin{array}{c}\text { RMSE } \\
\left(\mathbf{t} \cdot \mathbf{h a}^{-1}\right)\end{array}$ & d \\
\hline 123.7 & 135.1 & 20.9 & 0.92 \\
\hline
\end{tabular}

The results in Table 4 indicate that sugarcane yield was estimated well by the model. $\mathrm{S}_{\text {mean }}$ is slightly higher than $\mathrm{O}_{\text {mean }}$ and $\mathrm{d}$ is very close to a value of 1.0, indicating a high level of agreement between simulated and observed values. The RMSE of $20.9 \mathrm{t} \cdot \mathrm{ha}^{-1}$ means that, on average, yield was estimated within $16.8 \%$ of the observed value.

\section{Zimbabwe - Trial 4200/12}

The second set of trial data from Zimbabwe used for verification was from an irrigation trial conducted at ZSAES which was similar to Trial 4200/1 except that the soils were not virgin. The trial commenced in 1985 and was terminated in 1991. Six different irrigation treatments were applied, using pan factors ranging from 1.0 (Treatment 1 ) to 0.4 (Treatment 6 ).

\section{ERC yield}

A scatter plot of the data is shown in Fig. 6. Figure 6 shows that higher yields were slightly underestimated by the model and lower yields were slightly overestimated. The same observations made for Trial 4200/1 when analysing the relative ERC yields are applicable to these results and appear to be a common trend in the results simulated by the model. Statistical results of the ERC simulations are contained in Table 5.

\begin{tabular}{|c|c|c|c|}
\hline \multicolumn{4}{|c|}{ TABLE 5 } \\
$\begin{array}{c}\text { Statistical analysis of simulated vs. ob- } \\
\text { served ERC yield from trial } \\
\text { at ZSAES } \\
\text { ast }\end{array}$ \\
\hline $\begin{array}{c}\mathbf{O}_{\text {mean }} \\
\left(\mathbf{t} \cdot \text { ha }^{-1}\right)\end{array}$ & $\begin{array}{c}\mathbf{S}_{\text {mean }} \\
\left(\mathbf{t} \cdot \mathbf{h a}^{-1}\right)\end{array}$ & $\begin{array}{c}\text { RMSE } \\
\left(\mathbf{t} \cdot \mathbf{h a}^{-1}\right)\end{array}$ & d \\
\hline 15.43 & 15.77 & 1.60 & 0.92 \\
\hline
\end{tabular}

Unlike the previous trial data, actual ERC yields were well simulated for Trial 4200/12. The RMSE $1.60 \mathrm{t} \cdot \mathrm{ha}^{-1}$ indicates that, on average, yields were simulated within $10 \%$ of the observed value. The value of $d$ is very close to a value of 1.0 , showing a

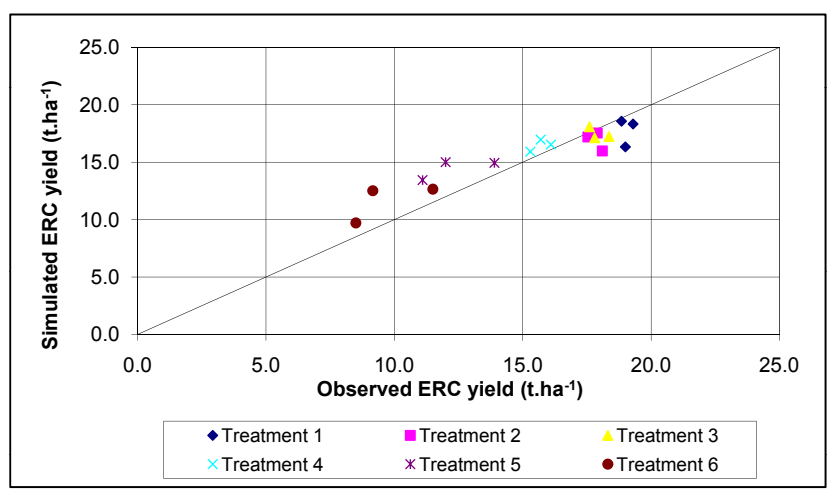

Figure 6

Observed versus simulated ERC yields from trial 4200/12 at ZSAES

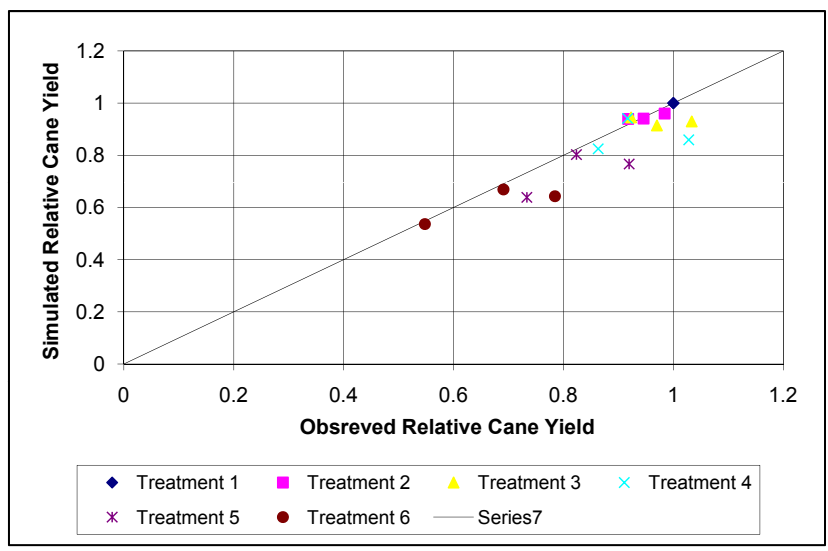

Figure 7

Observed vs. simulated relative sugarcane yields from trial $4200 / 12$ at ZSAES

very high level of agreement between simulated and observed values.

\section{Sugarcane yield}

Actual sugarcane yields were overestimated by ACRUCane. The mean observed yield was $112.4 \mathrm{t} \cdot \mathrm{ha}^{-1}$ compared to the mean simulated yield of $138.9 \mathrm{t} \cdot \mathrm{ha}^{-1}$. However, good correlations were obtained when relative yields were compared, as shown in Fig. 7. The results in Fig. 7 show a strong correlation between observed and simulated relative yields although there does appear to be a trend in underestimating the relative yields. A summary of the statistical analysis is contained in Table 6 .

\begin{tabular}{|c|c|c|c|}
\hline \multicolumn{4}{|c|}{ TABLE 6} \\
Statistical analysis of simulated vs. \\
observed relative sugarcane yield from \\
trial 4200/12 at ZSAES
\end{tabular}

As concluded from the results in Fig. 7, $\mathrm{S}_{\text {mean }}$ is marginally lower than the $\mathrm{O}_{\text {mean }}$. The RMSE of 0.074 means that, on average, relative yields were estimated within $8.3 \%$ of the observed relative value. The value of $d$ is very close to a value of 1.0 indicating a high level of agreement respectively between simulated and observed values. 


\section{Discussion of results}

Generally, the model's performance was adequate. In most instances actual yields for sucrose, ERC and cane were simulated well. Relative yields, i.e. yield trends were considered where the magnitudes of the observed yields were simulated poorly. Although ACRUCane models the irrigation water budget in detail, there are many aspects, which contribute to crop yield, which are not simulated by the model. Aspects such as soil quality (e.g. nitrogen content) and the existence of nematodes are examples of the variables which impact on crop yield and are not modelled explicitly by ACRUCane. However, simulating the relative differences in yield due to different irrigation treatments and seasonal climatic changes was considered the most important aspect of the verification study, as it is this feature of the model that enables it to provide decision support information.

A common trend observed in ERC and cane yield estimates was the overestimation of lower yields incurred by drier irrigation treatments. The reason for this was postulated to be the model's inability to simulate the impact of severe soil moisture stress on canopy development, as discussed in the paper. This limits the performance of the model under very dry conditions. However, it must be noted that the dry irrigation treatments simulated were not treatments that would typically occur in practice, unless the irrigator was forced to severely under-irrigate as a result of serious water shortages.

\section{Conclusions}

A core objective of this project was to integrate simulated crop water requirements, crop yields and the availability of water from a catchment, i.e. from a dam or directly from a river. Furthermore, these simulations needed to be representative of various water management and irrigation hardware systems. These objectives have been achieved and the results of the verification study show that the ACRUCane model performed adequately. Actual yields were captured accurately on most occasions. In instances where actual yields were not simulated well, relative differences in yield resulting from different irrigation treatments were represented well by the model.

ACRUCane has the potential to provide management information to a wide range of users. It should enable the expected performance of different types of irrigation and water management systems to be investigated. Furthermore, all of these can be assessed in relation to risks associated with available water supplies, water allocations and water transfer systems, thus providing information needed to assess the potential profitability of various irrigation alternatives. In terms of water resource assessments, ACRUCane could be used to determine the impact of irrigated sugarcane on water availability, for a range of irrigation systems and water management scenarios. Further development of the model to incorporate other crops and to account for more complicated operating rules governing water supply, for example, fractional water allocation and reservoir capacity sharing/water-banking is recommended.

\section{Acknowledgements}

The authors wish to record their sincere appreciation to $\mathrm{Dr}$ Abraham Singels and Dr Maurits Van Den Berg of the South African Sugarcane Research Institute (SASRI). Both gave very valuable input to various discussions, particularly relating to understanding the sucrose algorithm. Prof Roland Schulze, Dr Carel Bezuidenhout and Mr Sean Thornton-Dibb of the School of Bioresources Engineering and Environmental Hydrology, University of KwaZulu-Natal, also provided the lead author with very valuable assistance. Funding provided by SASRI is gratefully acknowledged.

\section{References}

ALLEN RG, PEREIRA LS, RAES D and SMITH M (1998) Guidelines for computing crop water requirements. Irrigation and Drainage Paper No. 56. FAO, Rome, Italy.

ASCOUGH GW and KIKER G (2002) The effect of irrigation uniformity on irrigation water requirements. Water $S A 28$ 235-242. http:// www.wrc.org.za/archives/watersa\%20archive/2002/April/1490.pdf

ASCOUGH GW and LECLER NL (2004) Benefits from performing irrigation system evaluations. In: Proc. S. Afr. Sugar Technol. Assoc. 78 263-272. Durban, RSA.

CAMPBELL GS and DIAZ R (1988) Simplified soil water balance models to predict crop transpiration. In: Bidinger FR and Johansen $\mathrm{C}$ (eds.) Drought Research Priorities for the Dryland Tropics. ICRISAT. Parancheru, India.

DE JAGER JM (1994) Accuracy of vegetation evaporation ratio formulae for estimating final wheat yield. Water $S A 20$ 307-314. http://www. wrc.org.za/downloads/watersa/1994/October/0833\%20abstract.pdf

DOORENBOS J and KASSAM AH (1979) Yield Response to Water. Irrigation and Drainage Paper No. 33. FAO, Rome, Italy.

INMAN-BAMBER NG (1991) A growth model for sugarcane based on a simple carbon balance and the CERES-Maize water balance. S. Afr. J. Plant Soil 8 (2) 93-99.

LECLER NL (2003) A model for the evaluation of irrigation and water management systems in the Lowveld of Zimbabwe: Model development and verification. In: Proc. S. Afr. Sugar Technol. Assoc. 77 322-333. SASTA, Mount Edgecombe, Durban, RSA.

LECLER NL, SCHULZE RE and GEORGE WJ (1994) Irrigation water supply and return flows. In: Schulze RE (ed.) Hydrology and Agrohydrology: A Text to Accompany the ACRU 3.00 Agrohydrology Modelling System. WRC Report No TT 69/95. Water Research Commission, Pretoria, RSA. pp AT18-1 to AT 18-8.

MOULT NG (2005) The Development of a Catchment Scale Irrigation Systems Model for Sugarcane. Unpublished M.Sc. Eng. Dissertation, School of Bioresources Engineering and Environmental Hydrology, University of KwaZulu-Natal, Pietermaritzburg, RSA.

McCOWN RL, HAMMER GL, HARGREAVES JNG, HOLZWORTH DP and FREEBAIRN DM (1996) APSIM: A novel software system for model development, model testing and simulation in agricultural systems research. Agric. Syst. 50 255-271.

MOULT NG, LECLER NL and SMITHERS JC (2009) A catchment scale irrigation systems model for sugarcane: Part 2 Model application. Water SA 35 (1) 29-36.

NWRS (2004) National Water Resources Strategy (1 $1^{\text {st }}$ edn.). Department of Water Affairs and Forestry, Pretoria, RSA.

SCHMIDT EJ and SCHULZE RE (1987) Flood Volume and Peak Discharge from Small Catchments in Southern Africa, Based on the SCS Technique. WRC Report No TT 3/87. Water Research Commission, Pretoria, RSA.

SCHULZE RE (1995) Hydrology and Agrohydrology: A Text to Accompany the ACRU 3.00 Agrohydrology Modelling System. WRC Report No TT 69/95. Water Research Commission, Pretoria, RSA.

SCHULZE RE, SCHMIDT EJ and SMITHERS JC (1993) SCS-SA User Manual. ACRU Report No. 40. School of Bioresources Engineering and Environmental Hydrology, University of KwaZulu-Natal, Pietermaritzburg, RSA.

SINGELS A and BEZUIDENHOUT CN (2002) A new method of simulating dry matter partitioning in the Canegro sugarcane model. Field Crops Res. 78 151-164.

SINGELS A, BEZUIDENHOUT CN and SCHMIDT EJ (1999) Evaluating strategies for scheduling supplementary irrigation of sugarcane in South Africa. In: Proc. of the Aust. Soc. Sugar Cane Technol. 21 219-226.

SINGELS A and DONALDSON RA (2000) A simple model of unstressed sugarcane canopy development. In: Proc. S. Afr. Sugar Technol. Assoc. 74 151-154. 
SINGELS A, KENNEDY AJ and BEZUIDENHOUT CN (1998) Irricane: A simple computerised irrigation scheduling method for sugarcane. In: Proc. S. Afr. Sugar Technol. Assoc. 72 117-122.

THOMPSON GD (1976) Water use by sugarcane. S. Afr. Sugar J. 60 593-635.
USDA (1985) Section 4, Hydrology. In: National Engineering Handbook. Soil Conservation Service, United States Department of Agriculture, Washington DC, USA.

WILLMOTT CJ (1981) On the validation of models. Phys. Geog. 2 184194. 